\title{
Cross Sectional Analysis of Biomarkers In Chronic Periodontitis Patients
}

M Yousaf ${ }^{1}$

Adil Yousaf $^{2}$

Farheen Khanum ${ }^{3}$

Saleha Gul ${ }^{4}$

Saira Gul
PhD

BDS

M.Phil

M.Phil

DVM

OBJECTIVE: To compare the serum level of Alkaline Phosphatase, Creatine Phosphokinase and Calcium level in male and female chronic periodontitis patients.

METHODOLOGY: In this study a cross sectional analysis of 40 male and 40 female chronic periodontitis subjects of various age groups, was conducted to assess the associated risk in term of bone loss and cardiovascular diseases by measuring serum Alkaline Phosphatase(ALP), Creatine Phosphokinase(CPK) and Calcium level. Serum Alkaline phosphatase (Normal value: 52-192 U/I) and Creatine phosphokinase (Normal value: 26-171U/I) were determined according to the International Federation of Clinical Chemist (IFCC) recommendations. Calcium ions (Normal value: 8.7-10.4 mg/dL) was determined by Spectrophotometric method Statistical analysis of the acquired data was carried out using SPSS 21.0 software and Microsoft Excel.

RESULTS: A higher mean serum level of ALP in both population group (Male: 195.45 U/I, Female: 203.92 U/I) was observed than normal level (52-192 U/I). The mean value of CPK was observed to be within the normal range for both the groups (Normal: 26-171 U/I) (Male: 143.82 U/I; Female: 122.58 U/I) but was higher for male population than the female population. The mean value of Ca was found to be $10.12 \mathrm{mg} / \mathrm{dL}$ for male subjects and $10.28 \mathrm{mg} / \mathrm{dL}$ for female subjects (Normal level: 8.7-10.4 mg/dL).

CONCLUSIONS: The results of this study suggest that female subjects are at greater risk of alveolar bone degradation than the male subjects while the higher mean values of serum CPK in male subjects put them at higher risk of cardio vascular disease than the female subjects.

KEY WORDS: Alkaline Phosphatase, Creatine Phosphokinase, Periodontitis, Calcium

HOW TO CITE: Yousaf M, Yousaf A, Khanum F, Gul S, Gul S. Cross sectional analysis of biomarkers in chronic periodontitis patients. J Pak Dent Assoc 2019;28(1):22-26.

DOI: https://doi.org/10.25301/JPDA.281.22

Received: 30 July 2018, Accepted: 03 October 2018

\section{INTRODUCTION}

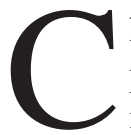
hronic periodontitis is the advanced stage of periodontal disease which leads to a significant loss in the supporting structure of teeth and their attachment at different stages. ${ }^{1,4}$ The disease is mostly common in adults but may affect all age groups depending upon the overall health status of an individual. ${ }^{5-7}$ The extent

1. Assistant Professor, Department of Biochemistry, Islamia College University Peshawar Pakistan.

2. Khyber College of Dentistry, Peshawar Pakistan.

3. Student, Department of Biochemistry, Islamia College University Peshawar Pakistan.

4. Lecturer, Department of Zoology, Islamia College Peshawar, Pakistan.

5. Lecturer, College of Veterinary Sciences and Animal Husbandry Abdul Wali Khan, University Mardan, Pakistan.

Corresponding author: “Dr. M Yousaf” < yousaf672010@ hotmail.com > of the tooth disease can be assessed by measuring the level of biomarkers in saliva, gingival fluid or serum of the patient. The important biomarkers in the diagnosis and prognosis of periodontal disease are micro-organisms, their products or enzymes derived from the host cells which are released during degradation of connective tissue. ${ }^{7}$ The biomarkers widely used to assess the oral health, are Alkaline Phosphatase (ALP), Creatin Phospho Kinase (CPK) and serum Calcium. Saliva, Gingival Crevicular fluid, serum and dental plaque are often utilized for the quantification of these biomarkers. Among these biomarkers Alkaline phosphatase (ALP) is one of the strong diagnostic marker for periodontal disease and is usually measured to determine the extent of tooth disease. ${ }^{9}$ Its activity in periodontal ligament is an important parameter 
in assessing the severity of the disease ${ }^{10}$ The high activity of ALP in periodontitis is the result of increase in bone turnover, bacterial plaque in periodontal pocket and inflammation. ${ }^{11}$

The activity of CPK increases in gingival inflammation and is considered as an important marker both in periodontal disease and cardiovascular diseases.

Shimazaki et al observed a significant negative association between normal serum CPK level and periodontitis in male subjects. ${ }^{12}$

Calcium is a potent biochemical marker for determination of decalcification and structural changes in alveolar bone, as calcium concentration rises in the patients with chronic periodontitis. In case of calcium deficiency desorption of alveolar bone show the initial structural changes in periodontitis. ${ }^{13,14}$

The potential role of ALP, CPK and Ca in measuring the extent and cause of periodontal disease could also be useful in measuring other diseases that are related to dental diseases.

Khyber Pakhtun Khwa is far behind in literacy rate, primary health care and other socioeconomic facilities. The dietary habits and unhealthy life style make them more vulnerable to various diseases including chronic periodontitis. We conducted this cross sectional analysis among male and female chronic periodontitis patients visiting Khyber College of dentistry in Peshawar Pakistan to compare their serum level of biochemical markers, the severity of the disease in both genders and also asses the associated risk of other diseases.

\section{METHODOLOGY}

This study was conducted in Khyber College of Dentistry (KCD) Peshawar from June 25, 2017 to August 18, 2017. The study was approved by the ethical committee of Khyber College of Dentistry, Peshawar. The subjects of the study include 40 male and 40 female confirmed periodontitis patients of different age groups visiting KCD for routine checkup. Informed consent was taken from each patient and information were collected on a standard questioner designed for this study.

Purposive sampling method was used in the selection of the study population. Five $\mathrm{ml}$ of fasting fresh blood sample was taken from all the patients and was analyzed for the quantification of serum ALP, CPK and Ca using standard methods.

Serum Alkaline phosphatase (Normal value: 52-192 U/I) and Creatine phosphokinase (Normal value: 26-171U/I) were determined according to the International Federation of Clinical Chemist (IFCC) recommendations. ${ }^{15,16}$
Serum Calcium ions (Normal value: $8.7-10.4 \mathrm{mg} / \mathrm{dL}$ ) was determined by Spectrophotometric method (complexation with Arsenazo) and its concentration was measured at 650 nm. ${ }^{17,18}$

Statistical analysis of the acquired data was carried out using SPSS 21.0 software and Microsoft Excel. Values were reported as mean \pm standard deviation. Pearson's correlation analysis was also done to find correlation between the variables of our interests. A two-tailed P-value $<0.05$ was considered statistically significant.

\section{RESULTS}

The age and BMI of study population are shown in Table 1. The mean age (40.52 years) and BMI $(24.70 \mathrm{~kg} / \mathrm{m} 2)$ of female population was slightly higher than the mean age (40.50 Years) and BMI $(24.70 \mathrm{~kg} / \mathrm{m} 2)$ of male population. Tea and soft drinks users were found higher in males $(92.5 \%)$ than females $(82.5 \%)$. The percentage of smokers was higher in males $(76.5 \%)$ than in female population $(05 \%)$ as shown in Fig 01.

Table 1: Age and BMI of the study patients

\begin{tabular}{|l|c|c|c|c|c|c|}
\hline S.No & Gender & Range & Min & Max & Mean & S.D \\
\hline \multirow{3}{*}{ Age(years $)$} & $\mathrm{F}(\mathrm{n}=40)$ & 54 & 22.00 & 76.00 & 40.52 & 16.17 \\
\cline { 2 - 7 } & $\mathrm{M}(\mathrm{n}=40)$ & 62.00 & 10.00 & 72.00 & 40.50 & 15.69 \\
\hline \multirow{2}{*}{ BMI $\left(\mathrm{kg} / \mathrm{m}^{2}\right)$} & $\mathrm{F}(\mathrm{n}=40)$ & 18.00 & 20.00 & 38.00 & 24.70 & 4.02 \\
\cline { 2 - 7 } & $\mathrm{M}(\mathrm{n}=40)$ & 16.00 & 20.00 & 36.00 & 24.57 & 3.28 \\
\hline
\end{tabular}

F: Female, M: Male, Min: minimum, Max: maximum, S.D: Standard Deviation

Fig 01: Comparison of tea, soft drinks users and smokers in study patients

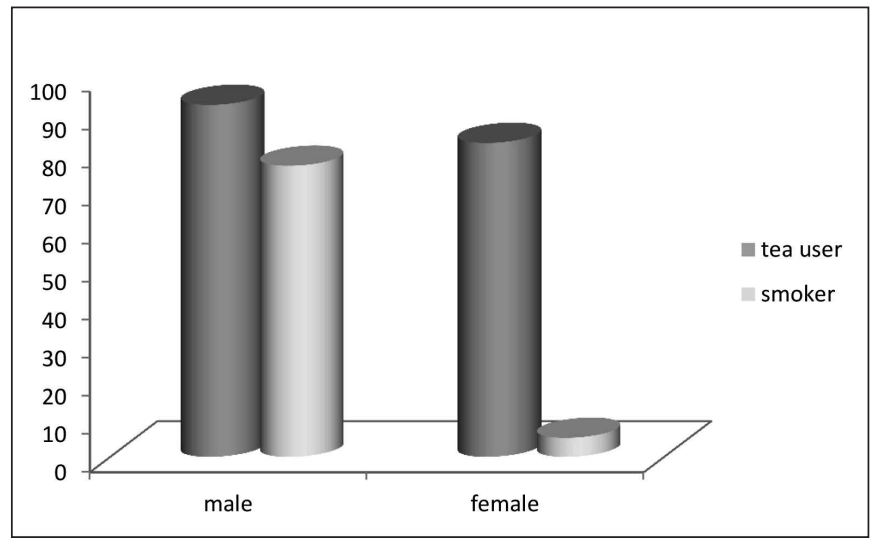

Mean values of serum ALP, $\mathrm{CPK}$ and $\mathrm{Ca}$ are given in table 2. The mean values of serum ALP (203.92 U/I) and Ca $(10.28 \mathrm{mg} / \mathrm{dL})$ was higher in female subjects as compared to the male subjects (ALP: $195 \mathrm{U} / \mathrm{I} ; \mathrm{Ca}: 10.12 \mathrm{mg} / \mathrm{dL}$ ). The 
Table 2: Comparison of ALP, CPK and Ca of the study patients

\begin{tabular}{|l|l|c|c|c|c|c|}
\hline S.No & Gender & Range & Min & Max & Mean & S.D \\
\hline \multirow{4}{*}{ ALP } & $\mathrm{F}(\mathrm{n}=40)$ & 478.00 & 87.00 & 565.00 & 203.92 & 86.95 \\
\cline { 2 - 7 } & $\mathrm{M}(\mathrm{n}=40)$ & 375.00 & 100.00 & 475.00 & 195.45 & 61.10 \\
\hline \multirow{3}{*}{ CPK } & $\mathrm{F}(\mathrm{n}=40)$ & 497.00 & 45.00 & 542.00 & 122.57 & 100.28 \\
\cline { 2 - 7 } $\mathrm{M}(\mathrm{n}=40)$ & 1287.00 & 33.00 & 1320.00 & 143.82 & 202.65 \\
\hline Ca & $\mathrm{F}(\mathrm{n}=40)$ & 4.75 & 8.46 & 13.21 & 10.28 & 0.90 \\
\cline { 2 - 7 } & $\mathrm{M}(\mathrm{n}=40)$ & 3.75 & 8.70 & 12.45 & 10.12 & 0.66 \\
\hline
\end{tabular}

mean values of serum CPK (143.82 U/I) was higher in male subjects than the female subjects (CPK: $122.57 \mathrm{U} / \mathrm{I})$.

Correlation analysis was used to find the association between the required variables and was expressed in term of coefficient of correlation(r). The results are presented in Table 3. Positive correlation was seen for ALP with age in both the groups. Negative correlation of ALP with BMI was

Table 3: Correlation analysis of the study patients

\begin{tabular}{|c|c|c|c|c|c|c|c|}
\hline \multirow{3}{*}{$\begin{array}{l}\text { Gender } \\
\text { F }\end{array}$} & \multirow[t]{2}{*}{ Parameter } & \multicolumn{2}{|l|}{ ALP } & \multicolumn{2}{|l|}{ CPK } & \multicolumn{2}{|l|}{$\mathrm{Ca}$} \\
\hline & & $\mathrm{r}$ & $\rho$ & $\mathrm{r}$ & $\rho$ & $\mathrm{r}$ & $\rho$ \\
\hline & Age & 0.269 & 0.094 & $0.497^{* \pi}$ & 0.001 & 0.000 & 1.000 \\
\hline & BMI & -0.163 & 0.315 & -0.163 & 0.316 & $0.402^{* *}$ & 0.010 \\
\hline \multirow[t]{2}{*}{ M } & Age & 0.012 & 0.943 & 0.205 & 0.204 & -0.217 & 0.178 \\
\hline & BMI & 0.130 & 0.422 & -0.033 & 0.815 & 0.135 & 0.407 \\
\hline
\end{tabular}

*. Correlation is significant at the 0.05 level (2-tailed).

**. Correlation is significant at the 0.01 level (2-tailed).

noted in females and positive in male subjects. Significant correlation of CPK $(p=0.001)$ was found with age in females while positive correlation was found for $\mathrm{CPK}$ in both the groups with other variables. Negative correlation of CPK was found with BMI in both male and female population. Significant correlation for $\mathrm{Ca}$ was observed with age and $\mathrm{BMI}$ in females $(\mathrm{P}=0.01)$.

\section{DISCUSSION}

Biochemical markers are important in the diagnosis of diseases when these are leaked as the immune system of body becomes weak. There are a number of evidences which suggests strong relationship between high serum ALP and low CPK level in periodontitis and high CPK level in patients with coronary heart diseases.

In this study a higher mean level of ALP was found in both the study group (Male: 195.45 U/I, Female: 203.92 $\mathrm{U} / \mathrm{I})$ than the normal level (52-192 U/I). This finding is accordance with the observations of Jaiswal et al (2016) and
Shaheen et al. ${ }^{19,20}$ They observed higher level of alkaline phosphatase among chronic periodontitis patients without any sub categorization of severity of the disease. Gibert also found higher serum level of ALP in both male and female patients. ${ }^{21}$

Mean values of CPK were found normal (26-171 U/I) for both groups (Male: 143.82 U/I; Female: $122.58 \mathrm{U} / \mathrm{I}$ ) but was lower for female than the male subjects. Lower levels of creatine kinase, higher level of $\mathrm{C}$-reactive protein and increased inflammation have been reported in patients suffering from severe periodontitis. It is believed that degradation of connective tissue in periodontitis leads to increase in release of creatine phosphokinase, thereby showing significant increase in chronic periodontitis subjects. ${ }^{22} \mathrm{We}$ observed a higher level of CPK in male patients as observed in other similar studies. ${ }^{23}$

The mean serum values of Ca were $10.12 \mathrm{mg} / \mathrm{dL}$ and $10.28 \mathrm{mg} / \mathrm{dL}$ for male and female subjects respectively (Normal range; 9 - $11 \mathrm{mg} / \mathrm{dL}$ ). In periodontitis patients, due to alveolar bone destruction, serum calcium level may increase as found in many research studies. ${ }^{24,25}$

Higher serum level of calcium was seen in male subjects as compared to female subjects in this study. The present study show that serum $\mathrm{Ca}$ has an important role in the formation of calculus which is carried by dental plaque and degree of attachment loss because the percentage of smokers in male subjects, soft drink and tea users was higher than females.

Periodontal diseases are strongly linked with cardiovascular and chronic kidney diseases, but the association is not very much clearly understood. ${ }^{26,27}$ The elevated level of CPK observed in this study add evidence in these relations and open up a new possible pathway in the complex puzzle that is a periodontal-systemic health relation. Periodontal disease is associated with many other diseases. ALP, CPK and Ca are not only used to detect the level/degree of dental diseases but are also used to measure the patient's overall health status. ${ }^{28,29}$

The potential role of ALP, CPK and $\mathrm{Ca}$ in measuring the extent and cause of disease could be useful in measuring other diseases that are related to dental diseases.

Chronic periodontitis get worsen with age along with other risk factors. Various risk factors which can induce periodontitis can be minimized by maintaining proper oral hygienic measures and our study concluded that lifestyle related risk factors associated with chronic periodontitis results in the progression of disease. Prevention is the better way of limiting diseases. Dental diseases are mostly related with the person's lifestyle.

The results of this study should be interpreted with caution to establish the mechanisms behind observed 
associations, as this study was conducted only on a limited number of subjects of Peshawar city only. Prospective studies involving larger population size are required to clarify the relationships between these serum markers and chronic periodontitis and their roles in the relationship between periodontitis and other diseases.

\section{CONCLUSION}

The results of our study suggests that female subjects are at greater risk of periodontitis and alveolar bone degradation in term of mean values of serum ALP and Ca than the male subjects while the higher mean values of serum CPK in male subjects put them at higher risk of

cardio vascular disease than the female subjects.

\section{CONFLICT OF INTEREST}

None to declare

\section{REFERENCES}

1. Mariotti A. Dental plaque-induced gingival diseases. Ann. Periodontol 2014;4:7-19.

https://doi.org/10.1902/annals.1999.4.1.7

2. Van Dyke TE. The management of inflammation in periodontal disease. J Periodontol 2013;79:1601-08.

https://doi.org/10.1902/jop.2008.080173

3. Armitage GC. Development of a classification system for periodontal diseases and conditions. Ann. Periodontol 2015;4:1-6.

https://doi.org/10.1902/annals.1999.4.1.1

4. Novak MJ. Classification of diseases and conditions affecting the periodontium. In: Newman MG, Takei HH, Carranza FA, eds. Carranza's Clinical Periodontology, 9th ed. WB Saunders Company; 2016;5:6473.

5. Fleming TF. Periodontitis. Ann. Periodontol 2016;4:32-8. https://doi.org/10.1902/annals.1999.4.1.32

6. Armitage GC. Periodontal diseases: diagnosis. Ann. Periodontol 2016;1:37-215.

https://doi.org/10.1902/annals.1996.1.1.37

7. Kinane DF. Blood and lymphoreticular disorders. Periodontol 2015; 21:84-93.

https://doi.org/10.1111/j.1600-0757.1999.tb00169.x

8. Rees TD. Drugs and oral disorders. Periodontol 2012;18:21-36. https://doi.org/10.1111/j.1600-0757.1998.tb00136.x

9. Gibert P, Tramini P, Sieso V, Piva MT. Alkaline phosphatase isozyme activity in serum from patients with chronic periodontitis. J Periodontal Res 2003;38:362-65.

https://doi.org/10.1034/j.1600-0765.2003.00388.x
10. Tonelli M, Sacks F, Pfeffer M, Gao Z, Curhan G. Relation between serum phosphate level and cardiovascular event rate in people with coronary disease. Circulation 2005,112:2627-33

https://doi.org/10.1161/CIRCULATIONAHA.105.553198

11. Kshirsagar AV, Moss KL, Elter JR, Beck JD, Offenbacher S, Falk RJ. Periodontal disease is associated with renal insufficiency in the Atherosclerosis Risk in Communities (ARIC) study. Am J Kidney Dis 2005;45:650-57

https://doi.org/10.1053/j.ajkd.2004.12.009

12. Shimazaki Y, Kushiyama M, Murakami M, Yamashita Y. Relationship between normal serum creatinine concentration and periodontal disease in Japanese middle-aged males. J Periodontol 2013;84:94-99.

https://doi.org/10.1902/jop.2012.110528

13. Van den Bos T, Beersten W. Alkaline phosphatase activity in human periodontal ligament: age effect and relation to cementum growth rate. J Periodontal Res 2015;34:1-6.

14. Zuabi O, Machtei EE, Ben Aryeh H, Ardekian L, Peled M, Laufer D. The effect of smoking and periodontal treatment on salivary composition in patients with established periodontitis. J Periodontal 1999;70:1240-46

https://doi.org/10.1902/jop.1999.70.10.1240

15. Schumann G, Aoki R, Ferrero CA, Ehlers G, Férard G, Gella FJ, Jørgensen PJ, Kanno T, Kessner A, et al.Clin Chem Lab Med. 2006; 44:1146-55.

https://doi.org/10.1515/CCLM.2006.212

16. Tietz Textbook of Clinical Chemisty and Molecular Diagnostics. Burtis, C.A., Ashwood, E.R., Bruns, D.E.; 5th edition, WB Saunders Comp., 2012.

17. Tietz N, W. Fundamentals of Clinical Chemistry; 3rd, Edition; W.B. Saunders Company: Philadelphia, 2013;43:676-79.

18. Beeler, M.F Catrou, P.G Disorders of Calcium Metabolism in Interpretations in Clinical Chemistry A.C.S.P. Press Chicago 2014; $54: 34-44$.

19. Jaiswal G, Deo V, Bhongade M, Jaiswal S. Serum alkaline phosphatase: A potential marker in the progression of periodontal disease in cirrhosis patients. Quintessence Inte. 2011; 4: 345-48.

20. Shaheen A, Khattak S, Khattak AM, Kamal A, Jaffari SA, Sher A. Serum alkaline phosphatase level in patients with type 2 diabetes mellitus and its relation with periodontitis. KUST Med J 2009;1:51-54.

21. Gibert P, Tramini P, Sieso V, Piva MT. Alkaline phosphatase isozyme activity in serum from patients with chronic periodontitis. $\mathrm{J}$ Periodontal Res 2003;38:362-65. https://doi.org/10.1034/j.1600-0765.2003.00388.x

22. Huang S, Dang H, Huynh W, Sambrook PJ , Goss AN. The healing of dental extraction sockets in patients with type 2 diabetes on oral hypoglycaemics: a prospective cohort. Aust Dent J 2013;58:89-93. https://doi.org/10.1111/adj.12029 
23. Maffuli PBN, Limongelli FM. Creatine Kinase monitoring in sport medicine. Br Med Bulle, 2016; 81: 209-30.

24. Novakovic N, Todorovic T, Rakic M, Milinkovic I, Dozic I, Jankovic S, et al. Salivary antioxidants as periodontal biomarkers in evaluation of tissue status and treatment outcome. J Periodontal Res. 2014;49:129-36

https://doi.org/10.1111/jre.12088

25. Nishida M, Grossi SG, Dunford RG, Alex W, Trevison M, Genco RJ. Calcium and the risk for periodontal diseases. J Periodontol 2010; 71:1057-66.

https://doi.org/10.1902/jop.2000.71.7.1057

26. Beck J, Garcia R, Heiss G, Vokonas PS, Offenbacher S. Periodontal disease and cardiovascular disease. J Periodontol 2013; 67:1123-1137. https://doi.org/10.1902/jop.1996.67.10s.1123
27. Khader YS, Albashaireh ZS, Alomari MA. Periodontal diseases and the risk of coronary heart and cerebrovascular diseases: a metaanalysis. J Periodontol 2004; 75:1046-53.

https://doi.org/10.1902/jop.2004.75.8.1046

28. Saremi A, Nelson RG, Tulloch-Reid M, Hanson RL, Sievers ML, Taylor GW, Shlossman M, Bennett PH, Genco R, Knowler WC. Periodontal disease and mortality in type 2 diabetes. Diabetes Care 2005; 28: 27-32.

https://doi.org/10.2337/diacare.28.1.27

29. American Diabetes Association. Diagnosis and Classification of Diabetes Mellitus. Diabetes Care 2012; 31 (Suppl 1): S55-60. 